\title{
COnE)-(oES
}

CIÊNCIA E TECNOLOGIA

\section{O QUALIDADE PÓS-COLHEITA DE MELÃO “TORREON” PARA EXPORTAÇÃO}

\author{
Francisca Deuzenir Marques Anselmo ${ }^{1}$, Ebenézer De Oliveira Silva ${ }^{2}$, Raimundo \\ WILANE DE FIGUEIREDO ${ }^{3}$ \\ ${ }^{1}$ Instituto Federal de Educação, Ciência e Tecnologia do Ceará - IFCE \\ 2 Embrapa Agroindústria Tropical - EMBRAPA \\ ${ }^{3}$ Universidade Federal do Ceará - UFC \\ <deuzenir@ifce.edu.br><ebenezer@cnpat.embrapa.br><figueira@ufc.br> \\ DOI: $10.21439 /$ conexoes.v15i0.568
}

\begin{abstract}
Resumo. Avalia-se a qualidade pós colheita de melões "Torreon" tratados com SmartFreshTM (1-Metilciclopropeno, 1 MCP) em relação ao armazenamento, visando a exportação. Os frutos são colhidos em estádio comercial na região produtora de Mossoró, no Rio Grande do Norte, sendo transportados sob refrigeração, para o Laboratório de Fisiologia e Tecnologia Pós colheita da Embrapa, Fortaleza-CE, onde são preparados para a aplicação de $1 \mathrm{MCP}$ gasoso em diferentes dosagens e períodos de exposição. Logo após, são armazenados, sob refrigeração, por 21 ou 28 dias. Extrai-se a polpa, que é homogeneizada para o doseamento de açúcares totais, açúcares redutores, $\mathrm{pH}$, acidez total e sólidos solúveis totais. Observa-se que em ambos os experimentos ( 21 e 28 dias de armazenamento refrigerado), os frutos tratados com $1 \mathrm{MCP}$, independente da dosagem, apresentam teor de SS ligeiramente inferior ao dos frutos não tratados (controle), o mesmo padrão é observado em relação aos açúcares totais e açúcares redutores, sendo o aumento do teor de açúcares uma das principais reações ao avanço do amadurescimento dos frutos. Podemos concluir que há retardo no amadurescimento e consequente aumento da vida útil dos frutos. Não há diferença significativa entre os períodos de armazenamento, ou seja, o melão "Torreon", quando tratado com 1-MCP pode ser armazenado tanto por 21 como por 28 dias sem prejuízo da sua comercialização.
\end{abstract}

Palavras-chaves: Cucumis Melo L..1-Metilciclopropeno. Refrigeração. Armazenamento. Pós-colheita.

\section{CANTALOUPS QUALITY POST-HARVEST "TORREON" FOR EXPORTATION}

\begin{abstract}
We evaluated the post-harvest quality of melons' Torreon' tratados with SmartFreshTM (1-methylcyclopropene, $1 \mathrm{MCP}$ ) in relation to the storage order to export. The fruits were harvested at commercial producing region in Mossoro, Rio Grande do Norte, being transported under refrigeration to the Physiology Laboratory and Post Harvest Technology from Embrapa, Fortaleza, where they were prepared for the application of $1 \mathrm{MCP}$ gas at different dosages and durations. Thereupon, were stored under refrigeration for 21 or 28 days. Extracted the pulp, which was homogenized for the determination of total sugar, reducing sugar, $\mathrm{pH}$, total acidity and total soluble solids. He noted that in both experiments ( 21 and 28 days of refrigerated storage), fruits treated with $1 \mathrm{MCP}$, regardless of dosage, SS content presented slightly lower than that of untreated fruits (control), the same pattern was observed for the total sugars and reducing sugars, and increasing the sugar content of the main reactions to the advancement of amadurescimento fruit, we can conclude that there was delay in amadurescimento and consequent increased shelf life of fruits. There was no significant difference between the storage periods, ie the melon "Torreon", when treated with 1-MCP can be stored either for 21 as for 28 days without damage of its commercialization.
\end{abstract}

Keywords: Cucumis Melo L., 1-methylcyclopropene, refrigeration, storage, postharvest.

\section{INTRODUÇÃO}

Segundo dados da FAO (2011), o melão é a oitava fruta produzida. Está entre as dez principais frutas frescas mais exportadas, com mercado internacional estimado em mais de 1,6 milhão de toneladas por ano.

Os melões nobres, especialmente o tipo Cantaloupe, têm sido bastante apreciados pelo mercado consumidor internacional, por serem melões mais saborosos e de alto valor nutritivo. Esses melões encontram boa aceitação, no mercado interno e externo, têm excelente potencial de produção, sendo por isso os mais produzidos no mundo (MENEZES et al., 2000).

A importância do melão como fonte geradora de divisas e empregos diretos e indiretos, e o aumento da produção e qualidade dos frutos para exportação, constitui-se uma das metas prioritárias do setor agrícola, nos Estados do Rio Grande do Norte e Ceará, lo- 
calizados no nordeste brasileiro (SEAGRI, 2011).

Um grave problema na comercialização de alguns cultivares de melão é a curta vida pós-colheita à temperatura ambiente, que impede a sua comercialização, nos mercados mais distantes, com as características de qualidade requeridas pelo consumidor (ALMEIDA, 2002). Deste modo, o desenvolvimento de novas tecnologias, que sejam capazes de promover uma maximização de produtividade da cultura sem perda de qualidade a custos reduzidos, são necessárias para que os produtores tenham condições de atender a demanda do mercado externo, especialmente o americano, o principal consumidor de melão (MENEZES et al., 2000). Dentre estas técnicas pode-se destacar a escolha do ponto ideal de colheita, além do uso de refrigeração, aliado a isso, o uso do 1-Metilciclopropeno (1-MCP) é uma forma de conservação, através da inibição do etileno, que têm dado bons resultados em outros frutos aumentando a vida útil pós-colheita, a fim de garantir um prolongamento da vida útil pós-colheita dos frutos.

O controle do amadurecimento pelo uso de um potencial inibidor da ação do etileno, associado à refrigeração, visando obter um produto final de elevada qualidade e com valor agregado, depende do estabelecimento da melhor concentração (dosagem) do regulador para cada produto, permitindo, assim, o desenvolvimento e a utilização economicamente viável da tecnologia. Espera-se, então, que o desenvolvimento de um pacote tecnológico, abrangendo a utilização eficiente do 1-MCP, possibilite a comercialização do melão "Torreon" em mercados mais distantes e dependentes de transporte marítimo por longas distâncias. Dessa forma o objetivo deste trabalho foi avaliar o período de comercialização pós-colheita de melões Cantaloupe, tipo , tratados com SmartFresh ${ }^{T M}(0,300$ e $600 \eta L$ $\left.\mathrm{L}^{-1}\right)$, por períodos seis ou doze horas, e armazenados sob refrigeração $\left(7 \pm 1^{\circ} \mathrm{C}\right)$, por 21 e 28 dias, objetivando não se ter prejuízos para exportação do produto.

\section{MATERIAL E MÉTODOS}

Os melões utilizados foram obtidos na Fazenda Agrícola Famosa localizada no município de Mossoró, Rio Grande do Norte, colhidos no estádio comercial. Em seguida, os melões foram transportados, via terrestre, em caixas próprias e sob refrigeração, de Mossoró para Fortaleza, para o Laboratório de Fisiologia e Tecnologia Pós-colheita da Embrapa Agroindústria Tropical. No laboratório, os frutos foram separados em lotes e colocados em câmaras plásticas de $0,186 \mathrm{~m}^{3}$, vedadas hermeticamente com tampas de acrílico, para a aplicação de $1 \mathrm{MCP}$ gasoso. O $1 \mathrm{MCP}$, na sua formulação em pó (3,3\% i.a.) foi pesado, em balança analítica, nas quan- tidades apropriadas para as concentrações gasosas de 0 , 300 e $600 \eta L \mathrm{~L}^{-1}$ (ppb), as quais foram acondicionadas em frascos, hermeticamente fechados, com tampas contendo septos para a aplicação (injeção) de água (na temperatura entre 40 e $60^{\circ} \mathrm{C}$ ). Após a dissolução do pó, o gás resultante foi aplicado ao produto, abrindo-se os frascos dentro da câmara de aplicação correspondente a cada dosagem. Imediatamente, as câmaras foram fechadas hermeticamente e mantidas em temperatura ambiente, expondo os frutos ao 1-MCP por seis e doze horas.

Após a aplicação do $1 \mathrm{MCP}$, os frutos foram acondicionados em caixas de papelão e armazenados por 21 ou 28 dias, na temperatura de $7 \pm 1^{\circ} \mathrm{C}$ e umidade relativa de $80 \pm 2 \%$. Após esses períodos de armazenamento refrigerado, os frutos foram transferidos para o ambiente $\left(25 \pm 3^{\circ} \mathrm{C}, 65 \pm 5 \% \mathrm{UR}\right)$, onde foram avaliados, a cada dois dias (um, três,cinco,sete e nove dias), com relação a parâmetros físico-químicos. Os melões foram separados em quatro fatias equidistantes de cada fruto, extraiu-se a polpa das mesmas até a região delimitante da parte comestível com a casca. Após homogeneização em processador doméstico, o suco foi armazenada em freezer para o doseamento de açúcares totais, açúcares redutores, $\mathrm{pH}$, AT e SS.

\subsection{Delineamento Experimental}

Para cada período de armazenamento refrigerado (21 e 28 dias), os experimentos foram conduzidos, separadamente, em delineamento inteiramente casualizado (DIC), com três repetições, num fatorial $3 \times 2 \times 5$, onde se estudaram os fatores: doses de $1 \mathrm{MCP}(0,300$ e $600 \eta \mathrm{L}$ $\mathrm{L}^{-1}$ ), tempos de exposição ao $1 \mathrm{MCP}$ (seis e doze horas) e tempos de armazenamento ao ambiente um, três, cinco, sete e nove dias).

\section{RESULTADOS E DISCUSSÃO}

Uma das exigências do mercado é que os melões sejam colhidos com teor de SS mínimo de $9{ }^{\circ}$ Brix, pois quanto mais doce o melão, melhor será seu valor de mercado (MENEZES et al., 2000). Os teores médios de SS observados durante o armazenamento neste experimento foram de 8,36 e $8,34{ }^{\circ}$ Brix, para os frutos armazenados por 21 e 28 dias, respectivamente, o que demonstra estar abaixo do limite mínimo exigido para o mercado. Os teores de SS observados para o híbrido "Torreon" neste experimento, apresentaram-se superiores aos encontrados por Brasil et al. (1998), de 7,7\% para melão Cantaloupe no mesmo estádio de maturação. Essa diferença de teores de SS pode ser explicada pelas diferentes condições de manejo e amostragem na 
hora da colheita.

Observa-se, na Figura 1(a), que os frutos controle apresentaram teor de sólidos solúveis, ligeiramente, superior aos frutos tratados, contudo essa diferença não foi significativa, em nenhum dos tratamentos, ao nível de $5 \%$ de probabilidade.

As curvas (Figura 1(b)) mostram que os teores de acidez variaram durante $o$ armazenamento, essa mesma variação não foi observada entre os tratamentos, houve a tendência ao declínio desses valores, obtendo-se em média $0,08 \%$ e $0,11 \%$ de ácido cítrico nas amostras armazenadas por 21 e 28 dias sob refrigeração, respectivamente.

Na maioria dos frutos, a acidez representa um dos principais componentes do flavor, pois sua aceitação depende do balanço entre ácidos e açúcares, sendo que a preferência incide sobre os altos teores desses constituintes (HOBSON; GRIERSON, 1993). No melão, a variação nos níveis de acidez tem pouco significado em função da baixa concentração e a intervenção da acidez no sabor não é muito representativa, podendo justificar a pouca atenção dada a esta variável.

A Figura 1(c) mostra que não houve efeito do tratamento com $1 \mathrm{MCP}$, pois os valores de $\mathrm{pH}$ dos frutos controle não diferiram dos valores dos frutos tratados. Já para os frutos tratados, os valores foram independentes da dose de $1 \mathrm{MCP}$ aplicada. Nota-se que praticamente não houve variação de $\mathrm{pH}$, nem durante $\mathrm{o}$ armazenamento e nem com o efeito do $1 \mathrm{MCP}$.

$\mathrm{O} \mathrm{pH}$ dos frutos controle e tratados apresentaram-se próximos e tiveram um aumento linear durante o período de armazenamento, não diferindo entre os dois períodos de armazenamento (21 e 28 dias), com pH iniciais e finais, para frutos tratados, de 6,32\% e 6,36\%; e de $6,32 \%$ e $6,48 \%$, para os frutos armazenados por 21 e 28 dias, respectivamente.

De acordo com a Figura 1(d), observou-se que não houve interação entre os fatores tempo e doses de 1 MCP, não ocorrendo também diferença estatística entre os tratamentos. Observou-se diferença apenas em relação ao tempo de armazenamento, cujos valores de SS/AT oscilaram durante o período experimental com tendência ao declínio.

A irregularidade da maturação dos frutos no campo é um dos fatores que contribuem para grandes diferenças nos teores de SS, implicando no comportamento da relação SS/AT.

A Figura 1(e) revelou que houve diferença apenas entre os frutos tratados e não tratados, ou seja, os teores de açúcares solúveis totais dos frutos tratados foram independentes da dose e do tempo de exposição ao 1MCP aplicado. Sendo os teores de açúcares solúveis totais dos frutos tratados menores que nos frutos controle.

Os teores de açúcares solúveis totais tiveram um decréscimo durante o período experimental, para todos os tratamentos, possivelmente devido ao consumo de substratos para o suprimento de energia das reações metabólicas. Fernandes (1996), em trabalho com melão Orange Flesh armazenado em temperatura ambiente (25 ${ }^{\circ} \mathrm{C}$ e $50 \pm 1 \%$ de U.R.), observou que houve redução no teor de açúcares solúveis totais, durante o armazenamento.

Os teores iniciais médios foram de $7,15 \%$, e ao final do período experimental eram de $6,63 \%$ nos frutos controle e $6,08 \%$ nos tratados.

Os teores de açúcares totais corresponderam a $87,63 \%$ dos teores de SS no início do armazenamento (tempo 0), e a $77,22 \%$ e $76,24 \%$ para frutos controle e tratados, respectivamente, ao término do período experimental.

A Figura 1(f) mostra que não houve diferença estatisticamente significativa, ao nível de 5\%, na variável açúcares redutores entre os tratamentos ao longo do tempo. Contudo, observou-se que os frutos controle apresentaram teores de açucares redutores maiores que dos frutos tratados durante o período experimental.

Essas variações podem ser devidas às transformações bioquímicas durante o amadurecimento e senescência do fruto quando ocorre ativação de enzimas catabólicas, interconversão de açúcares etc (PIZARRO; BENEDETTI; HAJ-ISA, 2006).

Pizarro, Benedetti e Haj-Isa (2006), trabalhando com melão Cantaloupe, minimamente processado armazenado em diferentes temperaturas e embalagens, encontrou comportamento semelhante para a variável açucares redutores.

\section{CONCLUSÕES}

Observou que em ambos os experimentos (21 e 28 dias de armazenamento refrigerado), os frutos tratados com $1 \mathrm{MCP}$, independente da dosagem, apresentaram teor de SS ligeiramente inferior ao dos frutos não tratados (controle). O mesmo padrão foi observado em relação aos açúcares totais e açúcares redutores, sendo o aumento do teor de açúcares uma das principais reações ao avanço do amadurecimento dos frutos. Podemos concluir que houve retardo no amadurecimento e consequente aumento da vida útil dos frutos. Não houve diferença significativa entre os períodos de armazenamento, ou seja, o melão "Torreon", quando tratado com 1-MCP pode ser armazenado tanto por 21 como por 28 dias sem prejuízo da sua comercialização. 
QUALIDADE PÓS-COLHEITA DE MELÃO “TORREON” PARA EXPORTAÇÃO

Figura 1: Teor de Sólidos Solúveis Totais (a), Acidez total (b), pH (c), Relação SS/AT (d), Açúcares Totais (e) e Açúcares Redutores (f) de melões Cantaloupe, híbrido "Torreon”", submetidos a aplicação pós-colheita de 1-MCP (0, 300 e 600 ppb) com 6 e 12 horas de exposição ao gás e armazenados por 21 ou 28 dias sob refrigeração $\left(7 \pm 1^{\circ} \mathrm{C}\right.$ e $80 \pm 2 \%$ UR), e monitorados a cada dois dias, em temperatura ambiente $(25 \pm 3$ ${ }^{\circ} \mathrm{C}$ e $65 \pm 5 \%$ UR)

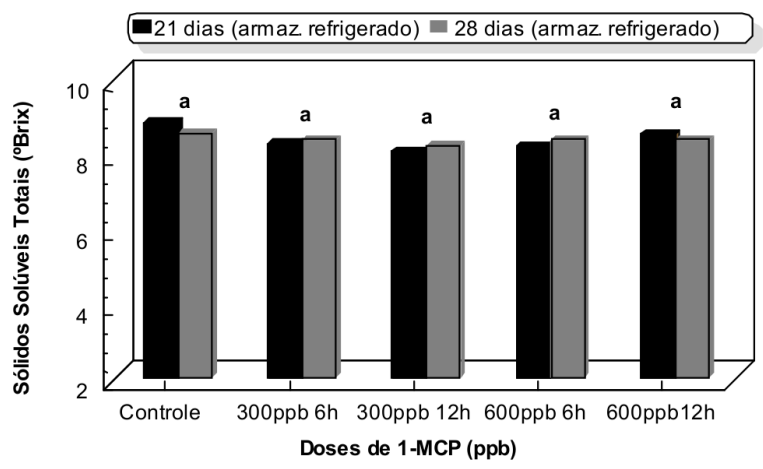

(a)

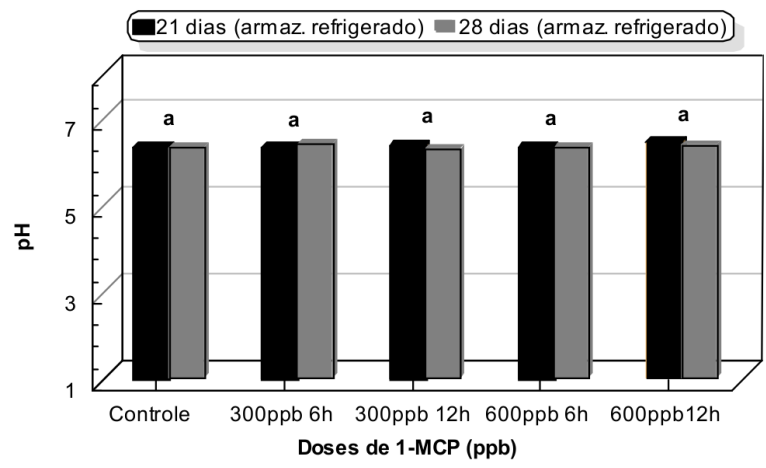

(c)

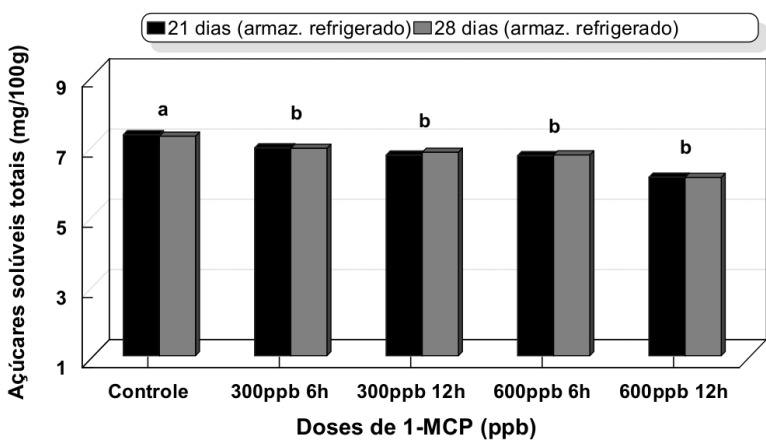

(e)

\section{REFERÊNCIAS}

ALMEIDA, A. S. Conservação de melão cantaloupe 'Hy-Mark' tratado com 1-MCP após a colheita. Dissertação (Mestrado em Agronomia) Universidade Federal Rural do Semi-Árido, Mossoró, 2002.

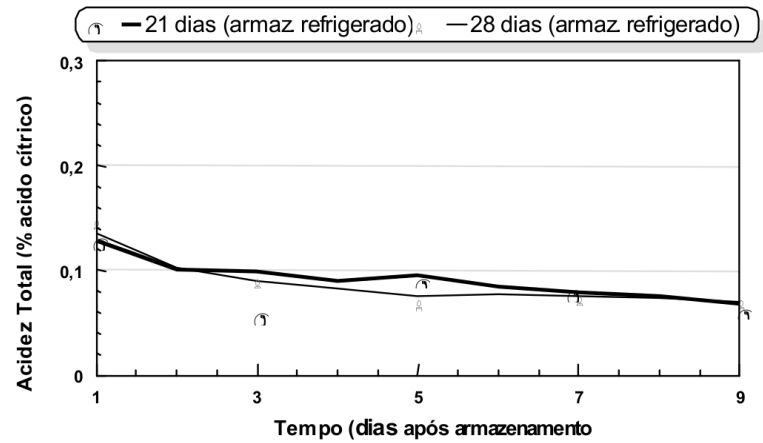

(b)

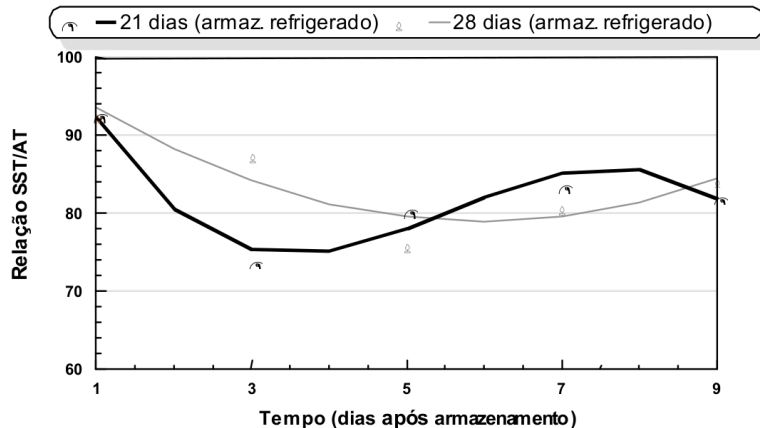

(d)

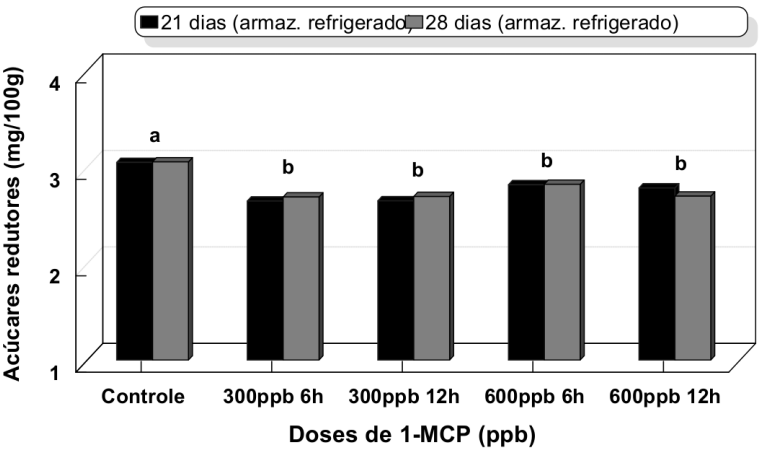

(f)

BRASIL, R. F.; PRAÇA, E. F.; MENEZES, J. B.; GRANGEIRO, L. C.; ALVES, R. Qualidade do melão "hy-mark" em cinco estádios de maturação. Horticultura Brasileira, v. 16, n. 2, p. 165-166, 1998.

FAO. Producción - cultivos primarios - melón. 
2011. Disponível em: <http://apps.fao.org> Acesso em: 20 jul. 2011.

FERNANDES, P. M. G. Armazenamento ambiente e refrigerado de melão, híbrido Orange Flesh, submetido à aplicação pós-colheita de cloreto de cálcio. Dissertação (Mestrado em Agronomia) Universidade Federal de Lavras, Lavras, 1996.

HOBSON, G. E.; GRIERSON, J. N. Biochemistry of fruit ripening. 1. ed. Londres: Chapman e Hall, 1993. 405-442 p.

MENEZES, J. B.; FILGUEIRAS, H. A. C.; ALVES, R. E.; MAIA, C. E.; ANDRADE, G. G.; ALMEIDA, J. H. S.; VIANA, F. M. P. Características do melão para exportação: Melão pós-colheita. 1. ed. Brasília: EMBRAPA-SPI/FRUTAS DO BRASIL, 2000.

13-22 p.

PIZARRO, C. A. C.; BENEDETTI, B. C.; HAJ-ISA,

N. M. A. Avaliação de melão minimamente processado armazenado em diferentes temperaturas e embalagens. Food Science and Technology, SciELO Brasil, v. 26, n. 2, p. 246-252, 2006.

SEAGRI. Exportações frutas frescas brasileiras: desafios dos fruticultores. 2011. Disponível em: <http://www.seagri.ce.gov.br> Acesso em: 22 jul. 2011. 